Acta vet. scand. 1969, 10, 101-103.

Brief communication

\title{
THE EFFECT OF CRIMIDIN ON REPRODUCTION IN HENS
}

The use of rodenticides as cereal baits involves the risk of intoxications of birds. The question as to whether the daily administration of sublethal doses of the $B_{6}$-antagonistic crimidin would influence reproduction in hens has been investigated in two experimental series.

\section{Forced feeding}

The material consisted of three groups of ten hens and two cocks, White Wyandottes, aged about 1 year, body weight 3-4 kg. Doses of $0 \mathrm{mg} / \mathrm{kg}, 1 \mathrm{mg} / \mathrm{kg}$ or $5 \mathrm{mg} / \mathrm{kg}$ crimidin ${ }^{\star}$ ) dissolved in $0.01 \mathrm{M}$ hydrochloric acid in a volume of $2 \mathrm{ml} / \mathrm{kg}$ body weight, were administered into the crop by a plastic tube six days per week for five weeks. Preliminary experiments showed that LD50 was about $10 \mathrm{mg} / \mathrm{kg}$ in these fully-grown hens, in contrast to chicks where Knudsen (1963) found LD50 to be $22.5 \mathrm{mg} / \mathrm{kg}$. The dose of $5 \mathrm{mg} / \mathrm{kg}$ often resulted in the prodromal symptoms ptosis and somnolence in the hens, while convulsions occurred only rarely.

T a b l e 1. Fertility and hatchability of eggs from hens fed cimidin for 5 weeks.

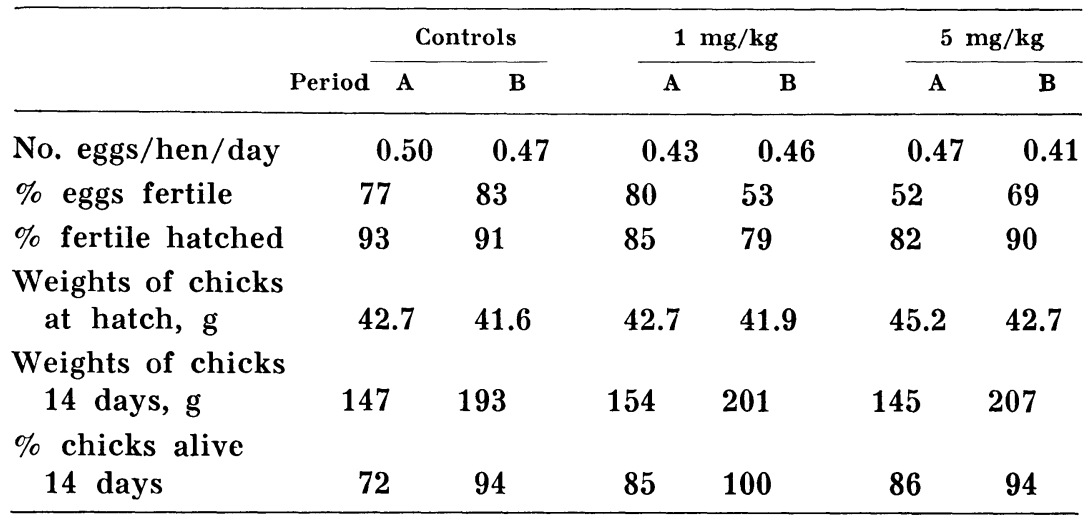

Eggs were collected for incubation in two periods, viz. A from the 7 th to 21 st days, and B from the 21st to 35th days. The results are shown in Table 1.

*) Crimidin = 2-chloro-4-dimethylamino-6-methylpyrimidine (ISO). 
It will be seen from the table that the fertilization percentage was reduced in period $B$ for the group given $1 \mathrm{mg} / \mathrm{kg}$ and in both periods for the group given $5 \mathrm{mg} / \mathrm{kg}$, while the hatching percentage, the growth rate of the chicks and the ability to survive were not affected. Adactylia was found in the left leg of one nonhatched chick in the control group, and schistosoma reflexum was demonstrated in one non-hatched chick in the $1 \mathrm{mg} / \mathrm{kg}$ group.

\section{Chick embryo test}

Doses of $0,10,100,300,600,800,1000,1600,2000,3200$ and $10,000 \mu \mathrm{g}$ crimidin in $50 \mu \mathrm{l}$ sterile distilled water per $60 \mathrm{~g}$ egg were injected before incubation into the yolks of groups of $32-39$ eggs of White Leghorns. Candling after seven days showed that $93 \%$ of the normal control eggs were fertilized. The fertilization percentage was also 93 in the group not given crimidin, while it was $90-97$ in all the eggs in which crimidin had been injected. The effect of crimidin on the hatching percentage will be seen from Fig. 1. A decrease was first observed with doses of 600 $800 \mu \mathrm{g}$ per egg. Using the slope for ED50 determination, the figure of $1150 \mu \mathrm{g}$ per egg is obtained. With an average weight of $60 \mathrm{~g}$ per egg and $42 \mathrm{~g}$ per chick, this value corresponds to $19 \mathrm{mg}$

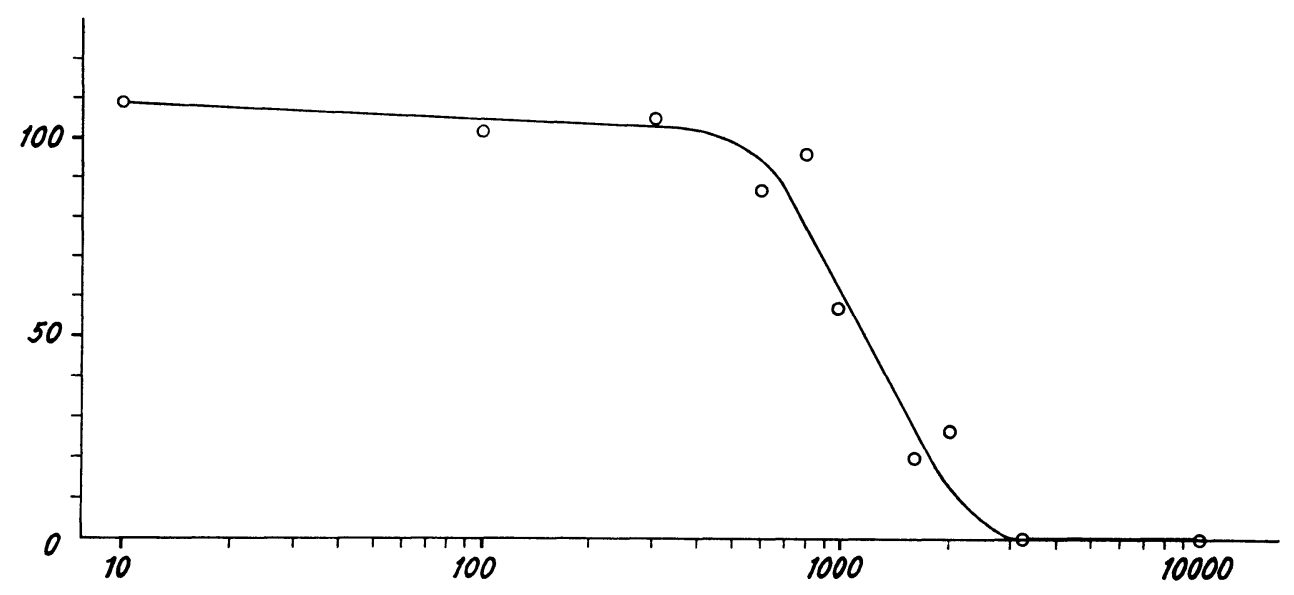

Fig u r e 1. Effect of crimidin injected into eggs prior to incubation.

Ordinate: $\frac{\text { Percentage hatch in the crimidin groups }}{\text { Percentage hatch in the O-crimidin group }} \times 100$

Abscissa: Crimidin injected $\mu \mathrm{g} / 60 \mathrm{~g}$ egg. 
crimidin per $\mathrm{kg}$ egg and $25 \mathrm{mg}$ per $\mathrm{kg}$ chick, which is quite close to LD50 for one-month-old chicks (Knudsen).

Deformities were not observed in the hatched chicks. In the $800 \mu \mathrm{g}$ crimidin group, one non-hatched chick had right-sided microphthalmia and left-sided anophthalmia. In the $1600 \mu \mathrm{g}$ group one chick had left-sided microphthalmia, one had bilateral microphthalmia, one had a deformed beak, and one had four legs, three wings and brain hernia. In the $3200 \mu \mathrm{g}$ and $10,000 \mu \mathrm{g}$ groups, the embryos died during the first half of the incubation period. In the $10-1600 \mu \mathrm{g}$ groups, the vitality of the hatched chicks was not different from that of the control group.

\section{CONCLUSION}

The daily administration of doses of $1 / 10$ to $1 / 2$ of LD50 crimidin to hens resulted in a reduction in the fertilization percentage. This is probably connected with the universal depressive effect on the hens provoked by such doses. The hatching percentage was not affected, and, as shown by the chick embryo test, such an effect became apparent only with concentrations of crimidin corresponding to 0.6 to $1 \mathrm{mg}$ per egg. It seems justifiable to assume that sublethal doses of crimidin under practical conditions do not influence reproduction in birds.

Sv. Dalgaard-Mikkelsen, O. Karlog and N. Gyrd-Hansen

The Department of Pharmacology and Toxicology, Royal Veterinary and Agricultural University,

Copenhagen, Denmark.

\section{REFERENCE}

Knudsen, E.: The toxicity of the rodenticide Castrix $®$ (2-chloro-4-dimethylamino-6-methylpyrimidine) and the antidotal effect of vitamin $\mathrm{B}_{6}$. Acta pharmacol. (Kbh.) 1963, 20, 295-302.

(Received February 3, 1969). 